\title{
POWER HOUSE AUTOMATION USING WIRELESS COMMUNICATION
}

\author{
Juhi Choubey $^{1}$, Priyank Sunhare ${ }^{2}$ \\ ${ }^{1}$ M. E Scholar, Department of Electronics \& Telecommunication, Shri Vaishnav Institute of Technology \& Science, \\ Indore, Madhya Pradesh, India \\ ${ }^{2}$ Assistant Professor, Department of Electronics \& Telecommunication, Shri Vaishnav Institute of Technology \& \\ Science, Indore, Madhya Pradesh, India
}

\begin{abstract}
The design is established for the automation of power house system. It shows how to remotely control and monitor power, automatically cut-off power on a single click using micro-controller based switches, wireless hardware module and web user interface during the shortage of power for power management or when bill is not paid. Web user interface shows complete information and power status of consumer stored in database; the data in a database is collected from remote module. To implement this, the wireless technologies used are IR module, zigbee module and server module through internet, PDA using graphical user interface and through smart phones. Static state relay for controlling power on/off outlets and sensors used to sense electric current being used by electric outlets. To measure power a measuring circuit senses the current and sends back a signal to the server module through zigbee the measured data is stored in embedded board and they are designed to become aware of any overload and to send a message to the circuit breaker for safety. PHP, JavaScript, html, CSS are used here to design a web user interface to provide a user-friendly operation of electric outlets. The proposed power outlet monitors the power consumption for the predetermined time and to completely cut-off power supply when the monitored power is below threshold. To efficiently manage the power outlets, the zigbee has several on board switches to wake up the power outlets and control them. The wireless communication module integrates several ac power sockets and a plug-in low power microcontroller performs power on/off switching of sockets. This system is used for power saving purpose and using wireless communication includes low cost, low data rate, self healing system and provides energy usage information to user on internet. The device works online so all the data are received in real time and the whole power system in home area can be managed in the remote area.
\end{abstract}

Keywords: Power house system, Switches, Relays, Wireless technology, HyperTerminal, Wamp Server, Net beans.

\section{INTRODUCTION}

In many countries communication based controlling and monitoring architecture is used to save power and have detectors and recorders to record power. Communication through wired interfacing and interconnection is very entangled and critical to install. To design this system wireless interface is used because it is easy to install and advanced than the previous one. Here, zigbee module is used which is a low power-consuming technology it covers $1 \mathrm{~km}$ range of area and data rate ranging from $20 \mathrm{Kbps}$ to $250 \mathrm{Kbps}$ which is very useful for remote controlling of electric power outlets of substations. Various hardware techniques are used for power controlling and monitoring based on current/voltage measuring circuits, micro controller unit (MCU) relay and zigbee Reduced Function Device (RFD). Here, power monitoring circuit measures power in real time and sends the information to MCU. After that Micro Controller scrutinize state of power and dispatch the information to the server module. For controlling purpose, traditional relay is superseded by static state relay and is annexed to the power monitoring hardware. After receiving the control command/message through smart phone, computer or laptop relay cuts-off the power supply to the electric power outlets. The observed power is recorded in Database management system which is accessed by the remote control module such as Smart Phones, Laptop, computer and a Personal Digital Assistance using Web user interface. The remote control module is entailed not only to control and monitor the power from power outlet but also to manage automation. A software module is designed here by the help of PHP, JavaScript, HTML and CSS which supports user to easily monitor the power outlet's condition that whether it is on or off. The remote controlling of electric appliances provides the ability to control through internet and the smart phones which is linked to server module to receive the control command or message for power management anywhere and anytime. By the help of software module all the power related content coming to this module can be connected to any PC or laptop. User can control power by combining software module and internet technologies to save power and by some little efforts. The database management system is used for collecting the data of consumers and stores it by the help of switches. When a consumer's bill is not paid in the defined time a message will be delivered by the software module the power connection will be cut-off by the help of relay, this system disconnects the power automatically. 


\section{RELATED WORK AND MOTIVATION}

Main advantage of the concept is its low cost, low-power consumption and energy conservation. Such a design can efficiently perform the remote power controlling and monitoring. Remote power disconnection automatically by the help of switches, software module, cut-off of the power and overload state which reduces labor and saves power, conserves energy that is the main feature of this project. Design of server module and software module using wireless communication technology for automatic disconnection is the challenging part of power controlling and monitoring, automation applications. These applications are widely used to reduce the power consumption by the help of wireless technologies like bluetooth, zigbee and many more devices. The main objective of this work is to disconnect the power automatically to reduce the manual work, save power and life of linemen, the system is designed for remote power controlling and monitoring. Many lineman dies due to contact with the energized line so this system will provide an option of software to save the manual work and risk of dangerous situation for a lineman. Nowadays, all the technical preventive aspects are well known, although electric accidents continue to occur. The averting of electric casualty has been viewed primarily as a technical concern, which can be ameliorating it by effective concoction. The motivation mainly comes from the record which shows that the death of linemen is because of the use of wrong components and equipment. There are many common incidents in electrical injury and on the spot current hurt injuries in which the use of various portable and faulty tools, open wire and unsafe electrical outlets are the reasons for the accidents. So, this is the concept of project; of automating this process using wireless communication and devices.

\section{HARDWARE AND SOFTWARE}

\section{ARCHITECTURE}

\subsection{Design of System Flow}

Fig 1 shows the basic design flow chart of power house control automation using wireless technology with brief elucidation. The foremost scrutiny is ingenious on wireless communication, web user interface module, zigbee network and embedded system. The relay function as per the message procured. For transferring information from zigbee FFD to zigbee RFD, RS232 is used. After, this authentication and authorization component verifies the identity and is used for security purpose. The system is leveled into various modules to implement the function stepwise. The block diagram of the overall system is shown in Fig. 2 with three modules. The main components of the system are switches, MCU, on-time power observing circuit, relay and zigbee network and software module.

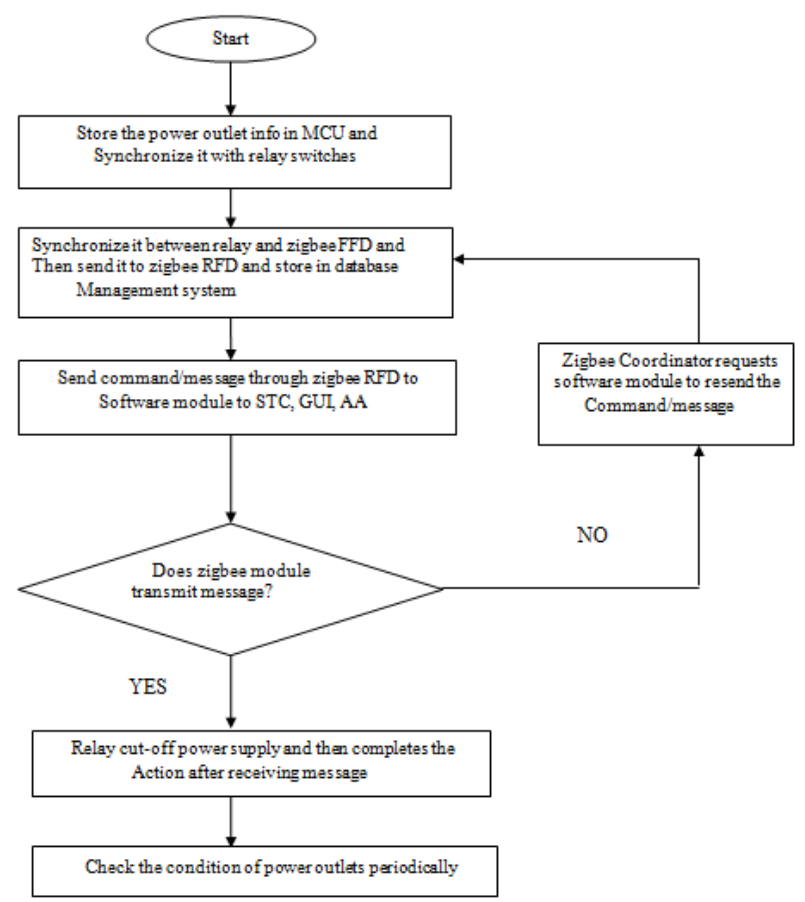

Fig 1: - Basic Work Flow of the System

\subsection{Hardware Setup}

The whole system is divided into three main modules and the three modules are further divided in sub modules which elaborate the system in a meticulous approach. Imperative hardware components are Analog to Digital Converter (ADC), Signal Transformation Circuit (STC), Authentication and Authorization Component (AA), Digital Signal Processing (DSP), relay switch and Distinctive Network Identifier (DNI). The modules are as follows:-

1) Power Controlling \& Monitoring Module

2) Web User Interface Module

3) Remote Control Module

First module accumulates the data imminenting from substation/center unit related to power in MCU and the power observing circuit observes the state in real time. The task of UART is to receive and transmit data in asynchronous way. The ADC converts the digital signal of current/voltage waveform of loads present in substations. The digital information are stored in internal memory and are used in calculating power consumption and another component of this sub module is DNI that is Distinctive Network Identifier which avoids collision between the data coming from several substations and provides security to it. The next sub modules is FFD (Full Function Device) which is used as coordinator or router which creates a network and transmit it to next module this feature of FFD is obtained by the tree network, the single module initially works on three network topologies that are mesh, tree and star.

Zigbee RFD (Reduced Function Device) acts as end device in next module where software module is present and GUI for creating user friendly environment. The command/message then pass through the web user interface module to remote control module and between them a 
zigbee network is used for synchronization and interfacing. After, obtaining the message relay switch connects the power supply. The fig - 2 shows the comprehensive block diagram of the proposed system this exhibits the components of different modules in details. For power controlling and monitoring microcontroller is programmed in such a way that each sub module is controlled through admin. And, is visualized when command is given on the experimental setup through the loads (bulbs) which directly unveil the condition of every house. Through GUI admin and consumers both can view the status and the admin can edit the data in database. Afterwards, remotely the status can be viewed by any consumer at any location through the website designed and the hardware and software setup are interlinked through visual basic's program to remotely control the database and commands given.

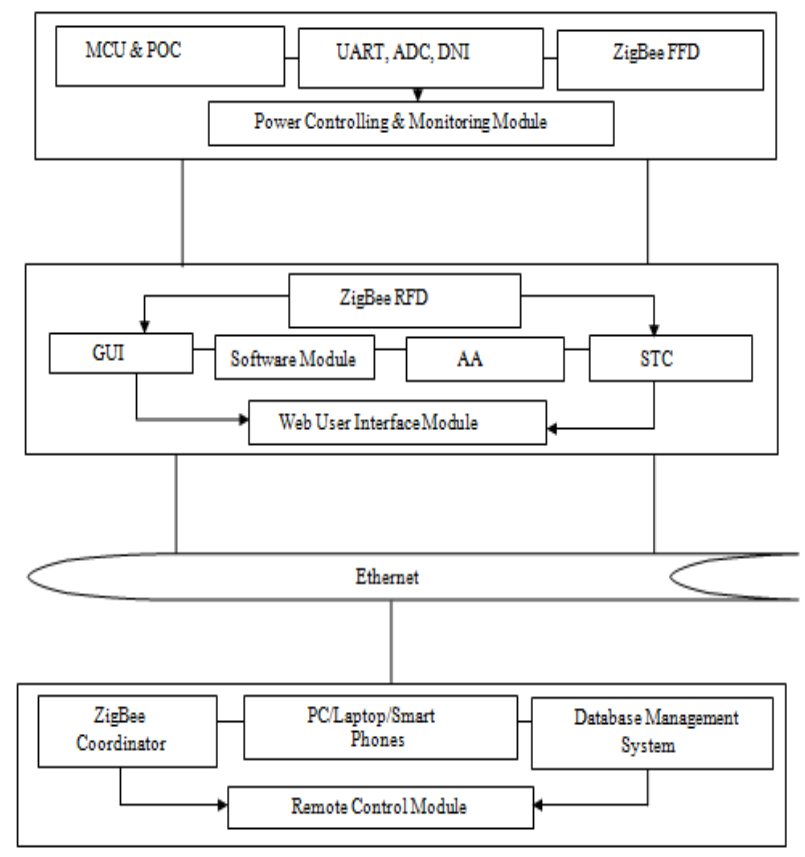

Fig 2:- Comprehensive Block Diagram of Proposed System

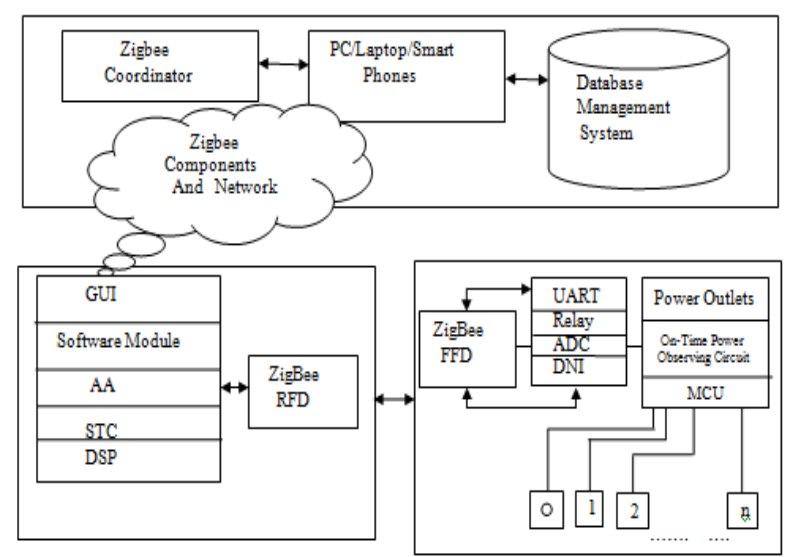

Fig.3: - Architecture of the Overall System
The Fig.3 describes the architecture of overall system containing sub modules that elaborates the system in a detailed way. The MCU is further divided in sub modules that are power controlling, power observing and interruption through message and record the whole data after use. If the message of disconnection occurs then, a message of interruption is given to it after that interruption duration is calculated. PHP is used to create software module and user friendly environment through GUI, the module is sub divided into several sub modules for creating software module and webpage. Tree topology is used to send data and control messages through the network using hierarchical routing. With the automating network of zigbee, zigbee FFD communicate easily with zigbee RFD. In Fig 4 pictorial setup of overall system is displayed to understand the working easily to show the step by step process from power generation to message implementation. In Fig.5 the flowchart describes how microcontroller is programmed to perform the action on loads connected with relay and LEDs. Here, port- $0,1,2$ of microcontroller is declared and port 3 is used in serial programming with database present in remote control module. After that, port pins are assigned to assorted relays one by one the bits are set. The main program begins now; first of all, some values are assigned to various ports to reset them with hexadecimal values. Now, timer and TMOD register of microcontroller are set according to the baud rate which is directly related with crystal used with microcontroller that is, 9600 bps (bits per second). Beside this, all the subroutines are designed such that all the LEDs and loads with respect to their relay will glow one after another, relay will also get disable by clicking on shift " $D$ " in such a way subroutines co-relate with each other. At this time a scanning process will transpire of scrutinizing all relays with some delay process. After this, the message of dispatching and receiving message will be obtained by PC/Laptop will be performed. Relay with loads define a house here in model, above description shows the working of model.

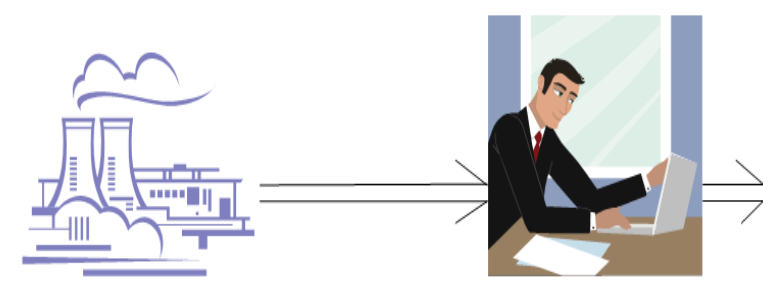

Power Station: - Generates Electricity

Computer Operator: - Execute Function According to Command Given
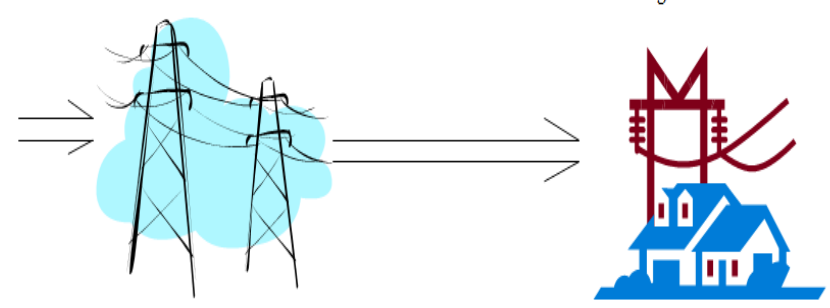

Board at Electric Pole: - Message Obtain at Board Present on Pole

House of Consumer Message Received \& Implemented

Fig 4: - Pictorial Representation of Overall System 


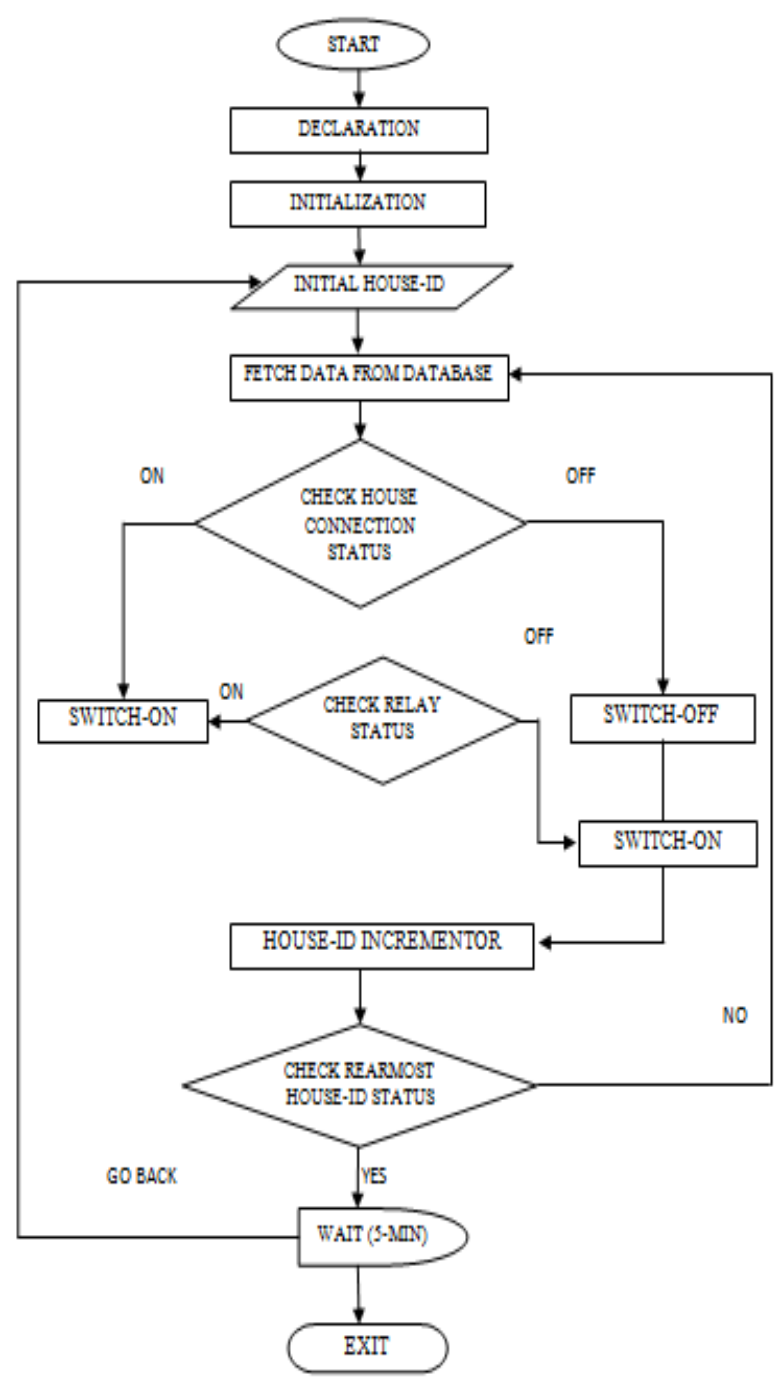

Fig 5: - Flowchart of Program Executed In Microcontroller

\subsection{Software Setup}

The software used for serial communication is hyper terminal for receiving and sending messages from relay to watch the condition of loads this software is used to overview the scenario of serially programmed data. The programming done on microcontroller is executed here step by step the status of loads are visualized. The software hyper terminal is used to make synchronization between commands given in the program and the performance of corresponding loads.

Now, a platform needed by the website to interface user and admin with each other after, the communication between the two person's decisions will be performed by admin at server present in power house. The website designed in PHP software, different scripts, various tags describing the admin side on web page that is server side by which admin is also creating dynamic pages for making different menus and includes various widgets and many more, this means that admin have the authority to make changes in consumers details and can take care of website along with its maintenance.

\section{WEB USER INTERFACE}

HTML, CSS coding shows the pages of website that will be displayed on client side. This coding is developed on net beans platform where database is located in phpmyadmin here admin will fill all the entries of users by making different tables into database and by pre-defining the type and value of data inserted into tables of corresponding database, here mysql holds database modules. For executing website admin can run it on local host, which is host of admin PC itself. The data from microcontroller is stored and is fetched to second module using python language. Power monitored by microcontroller connected to relays fetched from power controlling and monitoring module that is taken from microcontroller's port 3 and is serially transferred to web user module using python language. In Remote Control module all the data is stored in tables of the database, by opening the website client can obtain all the data regarding usage of power, credits and monitored power. In this website every user has individual and independent profile in reference of corresponding data of respective user which is private and present under highly secure mode using authentication and authorization code behind this context. The Figure-12 exhibited below delineates the rights of ingress of admin and user. In the website admin can perform different changes according to the need and situation as per the data and information present in the database regarding the consumers till due date. Now, in further steps admin allot user password as unique ID with which users/consumers can open their accounts to see the status. On the website page at server side the charts and tables are maintained with available data regarding the power usage, due date of bill, credits of consumers present in database and their corresponding accounts. Admin available at power house with website, only have the authority of making changes to the conditions according to the situation. And, the users can watch the profile; deposit the money of bill according to the power usage and can watch the status. The website have a direct wireless interfacing with hardware setup that is module- 1 on giving a single click on website of on/off the corresponding command to that click will perform the operation to related load which is representing a house itself, the cessation of the above process is to on/off the power of house according to the command given through website and also to monitor it. By the help of website consumer will become able to see the power status at that moment by just opening the authorized account after registering on the website which is absolutely commission free and reliable. The website contains all the previous and latest details of each and every consumer/user so that if in future he/she wants to see the details can just open the account and can go through the profile. Various new features are provided by us on advance payment of bill, bonus credits are provided which will be beneficial for consumer for long term cause. Our website provides flexibility between the consumer and maintenance in charge as admin present at server side of website. 


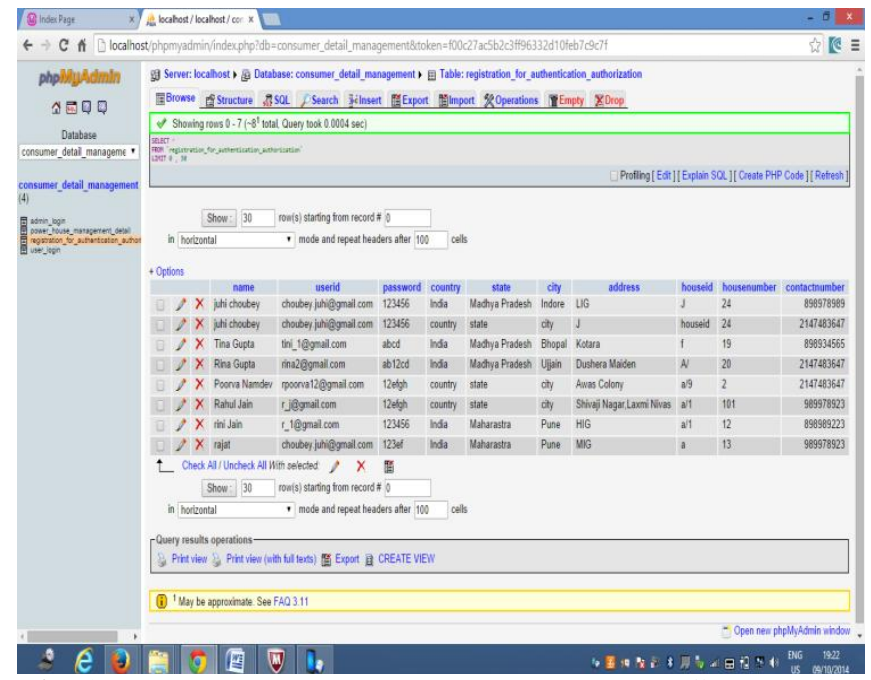

Fig 6: - Screenshot of Database Containing the Consumer's Details

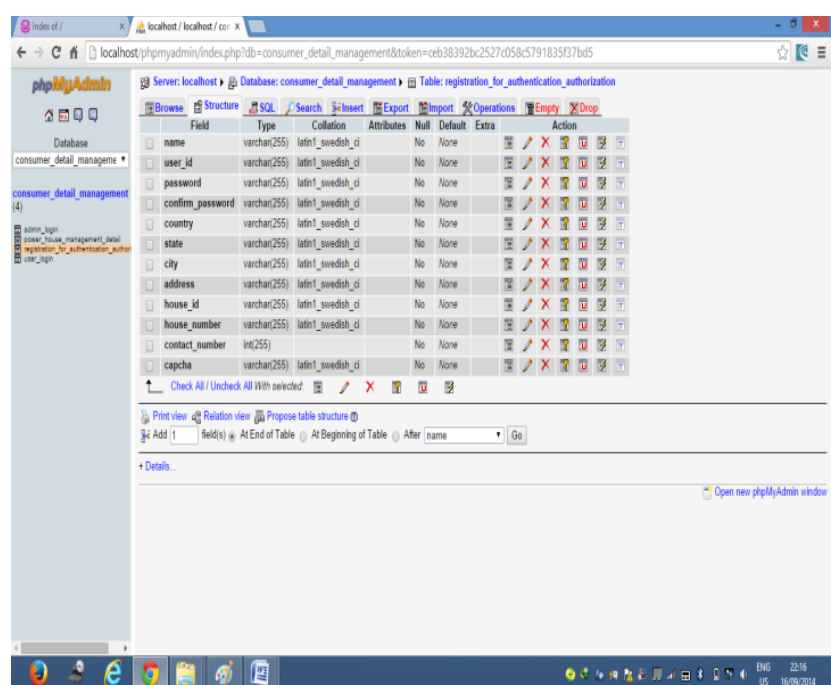

Fig 7: - Screenshot of Registration Table in Database for Authentication and Authorization

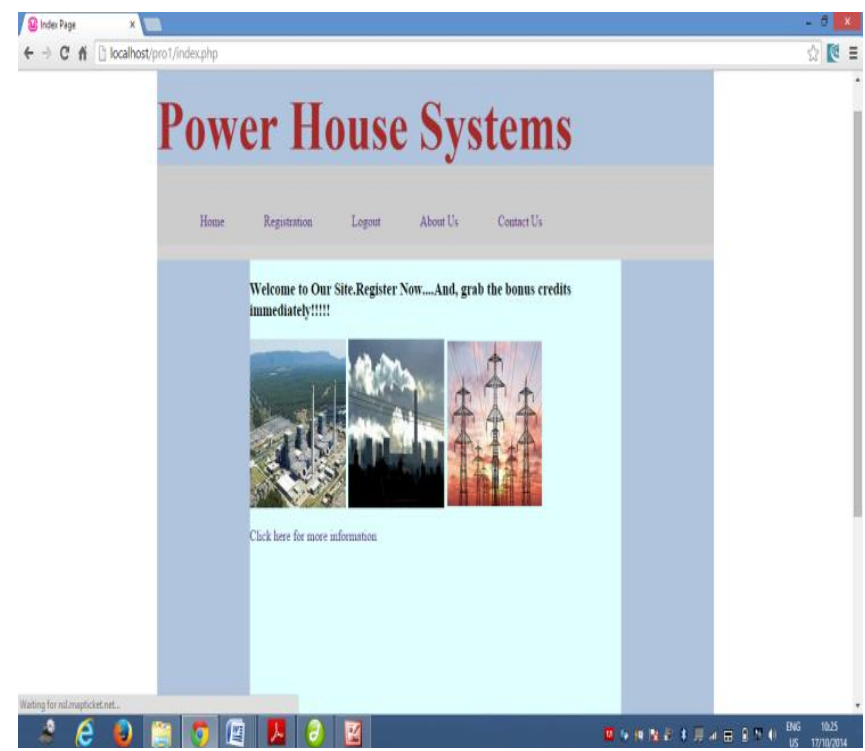

Fig 8: - Screenshot of Home Page of Website Home Page

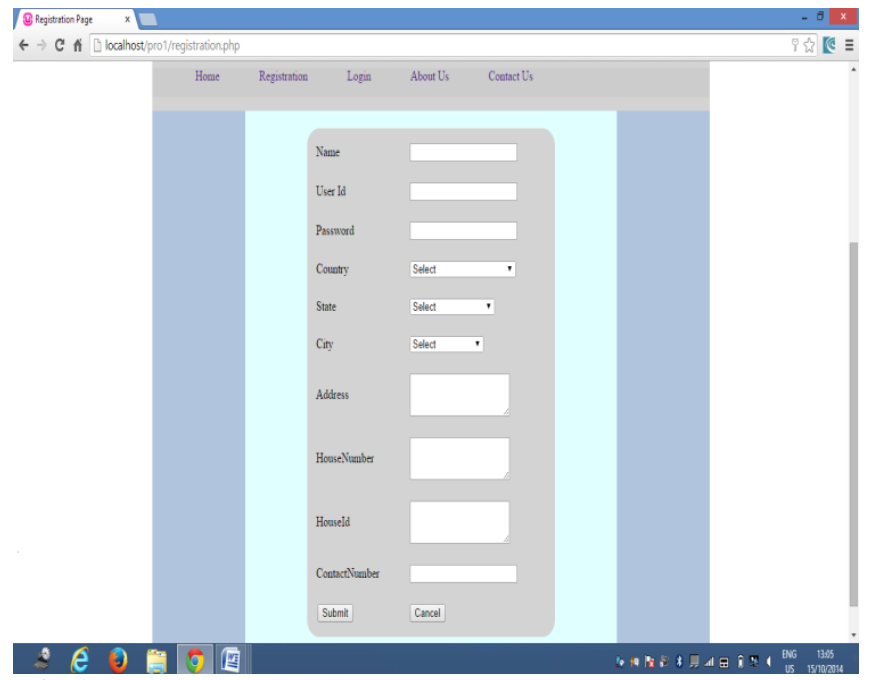

Fig 9: - Screenshot of Registration Page for Authentication \& Authorization of Consumer

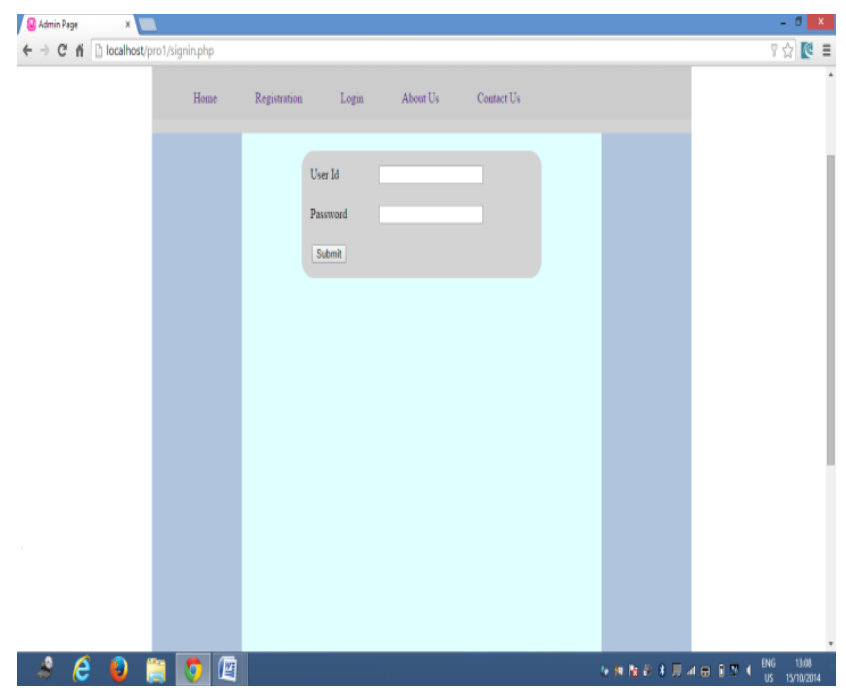

Fig 10: - Screenshot of Login Page to see the Status of Power Consumed

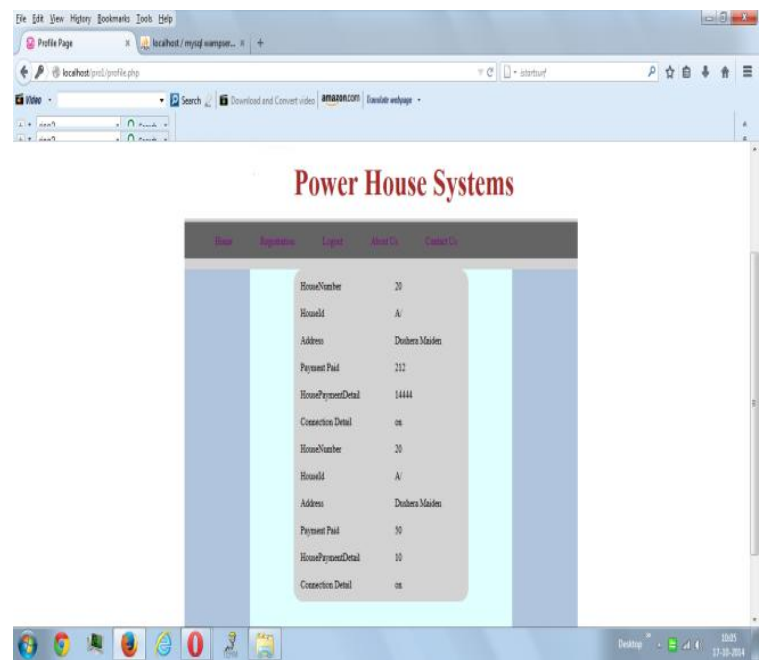

Fig 11: - Screenshot of Profile Page of Consumer on Website Showing Status 


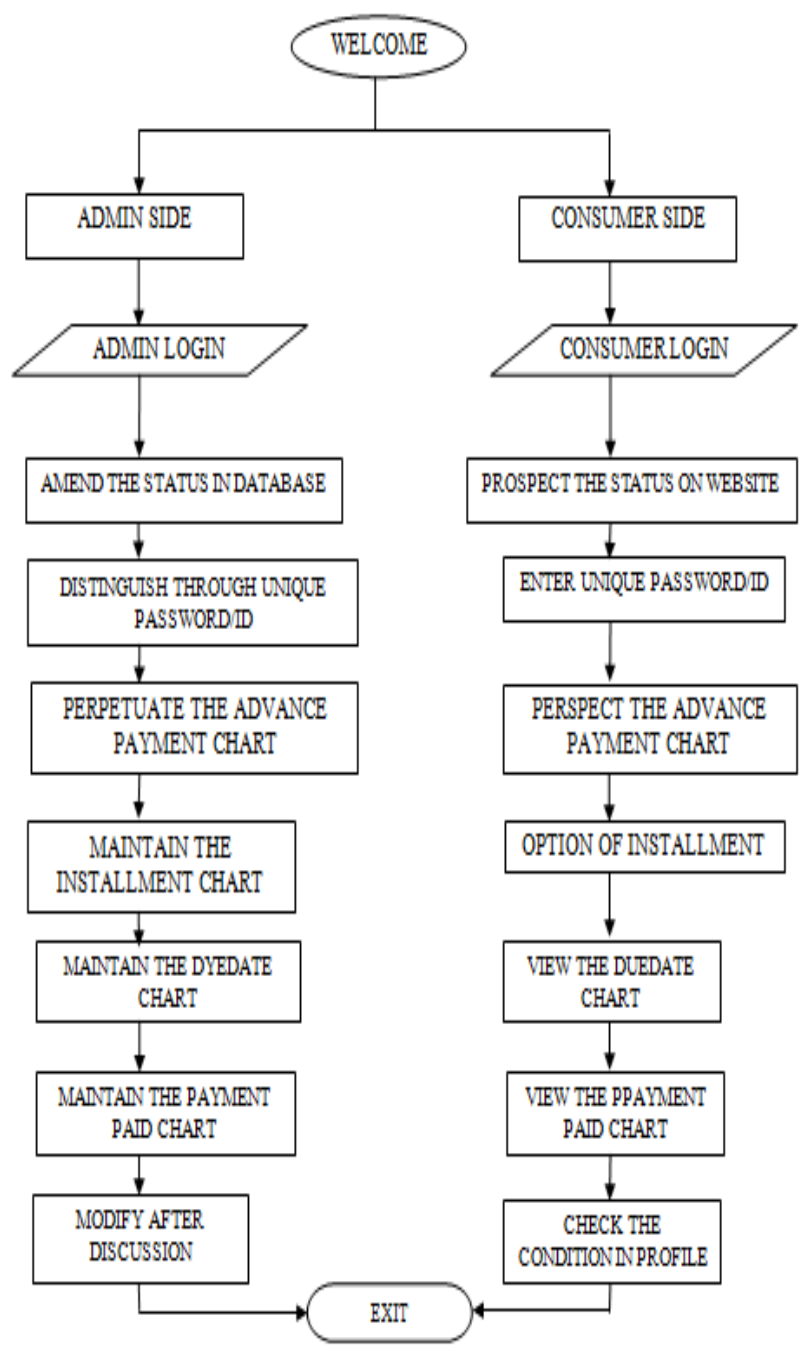

Fig 12: - Website Flowchart Module

\section{EXPERIMENTAL SETUP}

The proposed concept will be monitored and controlled by wireless switching actions executed by database and commands performed by microcontroller. This module display the status of consumer according to the due date and account balance of payment on website hosted. The status of various load corresponding to the relay are visualized here on server side as well as client side for limiting factors dependency. The microcontroller is programmed such that all light emitting diodes are connected to load and on/off according to the subroutines called by the database and board setup here interlinked through a website for the automation. The loads can be disabled whenever the instruction is delineated and are enabled whenever the situation of cut-off occurs. After, this in software data will be retrieved through experimental setup and every client after authentication can go through the account containing all data and information in tabular form. Here, in the figure given below the setup of microcontroller with DC Jack and DB-9 pin connector for power supply is displayed to perspicuously comprehend.

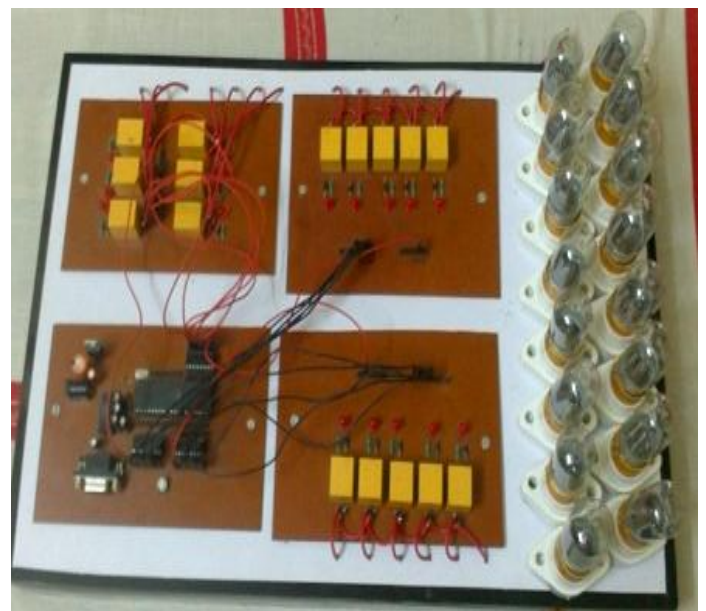

Fig 13: - Grid Control through Relay Setup (Module-1)
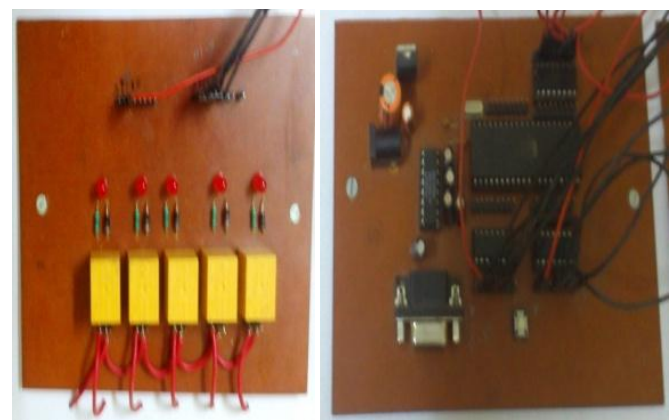

Fig 14: - Implemented Relay Setup with Loads \& Main Circuit of Microcontroller

\section{CONCLUSION}

This system provides automation in power disconnection field. The application of zigbee is used to provide low installation cost, low power consumption, mobility, rapid installation, remote location coverage and advanced wireless technology for the system automation. The role of zigbee is discussed in data transmission and receiving from power controlling module to web user module. This elaborates the use of smart phones/laptop to create user friendly environment. The system proposes remote disconnection and power saving architecture by this system overall power consumption is saved. The zigbee network provides speed to whole process and hierarchical structured modules. For efficient and secure power monitoring Authentication and Authorization component is used to avoid collision between networks and for their security DNI (Distinctive Network Identifier) is introduced in power controlling and monitoring module. The remote control module presents the key components for the system. The system will be integrated with the related hardware and software technologies and then tested. The main feature of the system is reliability, power saving and automation potential. Wireless technology is used because it provides communication in the place where there is no way to create wired network communication structure. Another advantage is it is mobile and can be moved from one place to other freely. The data of substations are collected in database management system which provides the collected information to the user through laptop/smart phones. 


\section{ACKNOWLEGMENTS}

The author would like to express the gratitude to Asst. Prof. Mr. Priyank Sunhare for his valuable support and professional guidance on this project. I would also like to thank Prof. Preet Jain HOD (Head of Electronics \& Telecommunication Department) for special assistance and guidance in keeping my progress on schedule.

\section{FUTURE WORK}

The project is based on wireless concept of technology the future aspects of this technology will be very vast when research will be performed. The zigbee technology will be considered as main concern towards the future work. Future work will consider the use of different ways of controlling and monitoring power, energy and data related to substations, their power outlets. Future work will include the new building blocks regarding this system and new prototypes will be created and testing of device in real time. This system provides user a GUI which makes the interface easily controllable and observable and tracks it. Nowadays, there is no initiative towards automation for disconnection, worker has to manually disconnect which is less efficient and provides less information. There is a growing concern for power controlling and monitoring through various methods using latest technologies for power automation.

\section{REFERENCES}

[1] "Remote Controllable and Energy Saving Room Architecture based on Zigbee Communication". IEEE Transaction on Consumer Electronics.

[2] "Zigbee Based Industrial Automation Profile For Power Monitoring System". International Journal on Computer Science and Engineering.

[3] Cheng, J.Y. and Hung, M.H. and Chang, J.W., "A zigbee based power monitoring system with direct load control capabilities", IEEE International Networking, Sensing and Control (INSC), 2007.

[4] Chen, B. and Wu, M. and Yao, S. and Binbin, N., "ZigBee Technology and Its Application on Wireless Meter-reading System", IEEE International Conference on Industrial Informatics, 2006.

[5] Zhang, Q. and Sun, Y. and Cui, Z., "Application and analysis of ZigBee technology for Smart Grid", IEEE International Conference on Computer and Information Application (ICCIA), 2010

[6] www.sersc.org,www.arxiv.org,www.zigbee.org.

[7] N.Javaid, A. Sharif, A.Mohammood, S.Ahmed, U.Qasin, Z.A.Khan "Monitoring and Controlling Power Using Zigbee Communications". Seventh International Conference on Broadband.

[8] Shizhuang Lin1, Jingyu Liu2 and Yanjun Fang," ZigBee Based Wireless Sensor Networks and its Applications in Industrial", International Conference on Automation and Logistics August 18 - 21, 2007, Jinan, China.

[9] Palak P. Parikh, Mitalkumar. G. Kanabar, Tarlochan S. Sidhu, IEEE Conference 2010, "Opportunities and Challenges of Wireless Communication Technologies for Smart Grid Applications"

\section{BIOGRAPHIES}

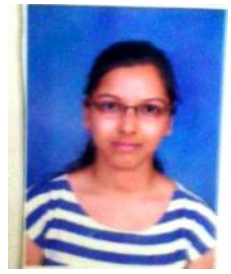

Ms. Juhi Choubey is pursuing M. E in Embedded System \& VLSI Design from Shri Vaishnav Institute of Technology \& Science (RGPV), Madhya Pradesh, India. She has completed B. E in Electronics \& Instrumentation from MITS; Ujjain affiliated to RGPV University, Bhopal, Madhya Pradesh with $75 \%$. Her research interest is power automation. Attended an International Conference on Emerging Trends in Instrumentation, Communication and Electronics and Electrical (ICE-ICEE) 2014 and workshop on MSP430 by Texas Instruments and is held at Shri Vaishnav Institute of Technology \& Science, Indore, Madhya Pradesh, India.

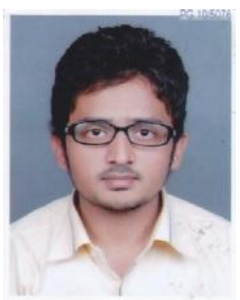

Mr. Priyank Sunhare is Assistant Professor in Shri Vaishnav Institute of Technology \& Science, Indore, (M. P), India. He has completed his $\mathrm{M}$. Tech from SoEx, Devi Ahilya Vishva Vidhyalaya in 2013, Indore, Madhya Pradesh, India with 8.21 (CGPA). He has also completed his B. E from Truba College, Indore. His reach interests are embedded systems and RTOS. 